\title{
A Study of the Solid-Liquid-Gas Three-Phase Coupling Relationship of Coal, Water and Gas
}

\author{
Anying Yuan (D), ${ }^{1}$ Chunhui Huang, ${ }^{2}$ Junling Hou, ${ }^{3}$ Zhaomin Zhang, ${ }^{2}$ Weihui Pan, ${ }^{2}$ Lei Duan, \\ and Quansen $W_{\mathbf{u}^{2}}$ \\ ${ }^{1}$ State Key Laboratory of Mining-induced Response and Disaster Prevention and Control in DeepCoal Mines, Anhui University of \\ Science and Technology, Huainan, Anhui 232001, China \\ ${ }^{2}$ Engineering Laboratory of Deep Mine Rockburst Disaster Assessment, Jinan Shandong Province, China \\ ${ }^{3}$ College of Vanadium and Titanium, Panzhihua University, Panzhihua 617000, China \\ ${ }^{4}$ Shandong Province Research Institute of Coal Geology Planning and Exploration, Jinan Shandong Province, China
}

Correspondence should be addressed to Anying Yuan; ayyuan@aust.edu.cn

Received 31 July 2020; Revised 19 August 2020; Accepted 29 August 2020; Published 15 September 2020

Academic Editor: Yixian Wang

Copyright (c) 2020 Anying Yuan et al. This is an open access article distributed under the Creative Commons Attribution License, which permits unrestricted use, distribution, and reproduction in any medium, provided the original work is properly cited.

\begin{abstract}
At the present time, it is of major significance to study the solid-liquid-gas three-phase coupling relationship of coal, water, and gas in deep-mining stopes in order to prevent and control coal and gas outbursts in high-gas mines. In this study, the influence rules of water on the mechanical characteristics of coal, as well as gas diffusion and migration processes, was examined by combining theoretical analysis and laboratory testing procedures. The results showed that with increases in water content, the mechanical characteristics of coal bodies presented change trends of first increasing and then decreasing. In this study, it was found that the water content levels which corresponded to the maximum shear strength of the coal in the No. 8 coal seam in the study area had ranged between $6.77 \%$ and $11.9 \%$, and the water content level corresponding to the extreme point was $8.66 \%$. It was observed that under different water content conditions, the gas desorption speeds of the coal bodies gradually decreased over time. The gas desorption speeds rapidly decreased during the initial desorption stage and then gradually decreased over time. Furthermore, under the different water content conditions, the amount of gas desorption in the coal bodies was observed to gradually increase over time, with the initial desorption amounts displaying rapid increases. Then, with the passage of time, the increase speeds of the gas desorption amount gradually decreased and finally tended to remain at a stable value. It was found that with the increases in water content, the desorption speeds, initial desorption speeds, and desorption amount of gas in the coal bodies continuously decreased. In other words, the water content levels in the coal bodies were negatively correlated with the gas desorption speeds and desorption amounts of the coal bodies. In addition, the gas desorption speeds, initial desorption speeds, and desorption amounts were observed to change more sharply with the increases in water content. The results of this research hold important guiding significance for the improvement of the understanding of the mechanical properties of highgas coal seams and the implementation of effective gas control measures.
\end{abstract}

\section{Introduction}

Coal gas is a type of unconventional natural gas which is mainly stored in coal fractures and pores in an adsorption state. The mechanical characteristics of coal, along with the diffusion and migration characteristics of gas, are closely related to the water content in the coal bodies $[1,2]$. Therefore, as a type of fluid medium for gas-bearing coal, water can create an occurrence environment of a solid-liquid-gas three-phase coupling after entering the coal bodies. The characteristics of the water stimulate the unique and complex action mechanisms of coal seam water injection technology and have the application value of integrating multiple functions into one function [3-5].

When water intrudes into coal bodies, the mechanical properties of the coal bodies can change. In addition, the stress distributions of the stopes and the gas adsorption and desorption performances of the coal bodies may be altered. 
In accordance with the laboratory test and empirical field study results, it is generally believed that outburst risks will be weakened when the water content of the outburst coal seams is increased to a certain degree [6-8]. It was determined in previous research investigations that loose and soft coal bodies are characterized by micropore development, poor pore connectivity, small lumpiness, and abundant fine particles due to the influences of tectonic activities. As a result, the agglomeration and cementing of particles after water injection treatments tend to promote the enhancement of the coal body strength $[9,10]$.

It has been revealed through extensive field tests and laboratory simulations following water injections, the concentrated stress in front of mine working faces will move forward. Moreover, the factor of the stress concentration decreases, and the pressure relief zones become wider, thereby allowing the elastic potential energy in the coal bodies to be alleviated. Generally speaking, the plasticity is enhanced, and the resistance to outburst risks is improved overall [11-13]. However, it is considered that residual water in the pores will block the gas migration channels after water injections, which will have certain impacts on the gas release rates [14-16]. It is also considered that the inhibition effects on gas desorption of water may be due to the fact that the capillary force reduction effects caused by the amplification of pore channels by pressure water is generally smaller than the capillary force increase effects caused by the original pore scales [17-19]. The results of gas diffusion experiments have indicated that the gas desorption amounts and desorption speeds will be affected to a certain extent when the water content levels in coal bodies are higher.

There are many types of technology and methods currently adopted to increase water content levels in coal bodies. These mainly include coal seam water injections, hydraulic cutting, hydraulic fracturing, hydraulic punching, hydraulic extrusions, and hydraulic channeling. From a mechanical point of view, the above-mentioned methods use water pressure levels which are higher than the formation stress or coal failure resistance in order to impact the coal bodies and cause fracturing and pore openings to occur. These repeated disturbances are referred to as "compression-expansioncompression" disturbance and have been found to improve the permeability of reservoirs. With the implementations of hydraulic permeability improvement processes, the water content levels in the coal bodies will inevitably increase, which will affect the adsorption and desorption processes of coal gas to a certain extent [20-24].

In the above study, the mechanical characteristics of moisture on coal and the change characteristics of moisture on gas adsorption and desorption performance were studied by various methods. However, the specific laws, degrees, and quantifications of the influencing effects of water on coal gas adsorption and desorption require further examination. The specific influence rules of different amounts of water content on the mechanical characteristics of coal had not yet been fully revealed. The coupling relationship between the gas diffusion and migration processes and the mechanical characteristics of the coal under different water content conditions also needs further clarification.

\section{Analysis of the Influence Mechanisms of Water in Regard to the Mechanical Characteristics of the Coal Bodies}

It has been determined that liquid bridge force is formed by the overlapping effects of water molecules between coal particles, and the content of the water molecules will determine the size of the liquid bridge force. It has been observed that, for the majority of the coal particles, since the partial pressure of the ambient water vapor is higher than the saturated vapor pressure on the surfaces of particles in humid air environments, the supersaturated water vapor can easily condense into liquid water on the surfaces of particles and form a water film. The thicknesses of water film on the particle surfaces are dependent on the relative humidity of the air and wettability of the particle surfaces. For example, the higher the relative humidity in the air environment is, the stronger the hydrophilicity of the particles will be, and the thicker the water film on the surfaces of the particles will be. Then, when the particles with water film come into contact with each other, the liquid bridge force will be formed at the contact point of the particles [25].

Liquid bridges will be formed between the coal bodies and the water after mixing and contact actions, and the liquid bridge force will affect the mechanical characteristics of the coal bodies. Therefore, the mechanical characteristics of the coal bodies will inevitably change with any changes in the water content levels. Figure 1 shows the form of liquid bridges between wet coal particles.

When the water content levels of coal bodies are within a small range, some of the strong hydrophilic particles in the coal particles will first begin to form liquid bridges with the water. Then, as the water content gradually increases, the number of liquid bridges formed by the coal particles and water will also increase correspondingly. As the total liquid bridge force increases, the strength of the coal bodies also increase. For example, when the water content levels are large and the water amount continues to be increased, the liquid bridge force between the particles will change from a suction force to a repulsion force. As a result, the total liquid bridge force will be reduced, along with the strength of the coal bodies.

\section{Analysis of the Influence Mechanisms of the Water in Regard to the Gas Adsorption and Desorption Processes of the Coal Bodies}
3.1. Analysis of the Existence Forms of the Water Content within the Coal Bodies. In this field of study, the water within coal bodies is generally divided into three forms according to the existence state as follows: external water, internal water, and combined water. The external water refers to the water attached to the coal particle surfaces, as well as that adsorbed by the large capillaries on the coal body surfaces. The external water combines with the coal in mechanical way. This is only related to the external conditions, but not to the coal quality itself. When coal particles become dry in the air, the external water of the coal is easily evaporated until the vapor pressure 


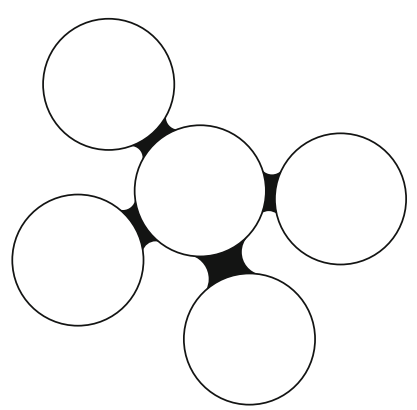

Figure 1: Liquid bridges between wet granular coal particles.

on the coal surface becomes balanced with the relative humidity of the air. Therefore, the external water does not affect the gas adsorption amounts and gas diffusion coefficients of the coal particles. The internal water is the water absorbed by the inner small capillaries of the coal, and the water in this state cannot be lost at normal temperatures. However, the internal water can be potentially lost when heated to a certain temperature. The larger the inner surface areas of the coal is, the more capillary tubes there will be and the higher the internal water content will be. It has been determined that the internal water is the main factor affecting the adsorption of gas by the coal. The combined water refers to the water existing in a combination form with the mineral compositions of the coal. It is considered that the gas adsorption capacities and diffusion coefficients of coal particles are not affected by the water in a combined state. Therefore, it was considered in this study that the internal water was the main factor affecting the gas diffusion law [26].

3.2. Influence Mechanisms of the Water in Regard to the Gas Adsorption of the Coal Bodies. It is known that there is a direct relationship between the gas limiting diffusion amounts and the gas adsorption amounts, as shown in Formula (1). In this study, the influences of water on the gas adsorption amounts were mainly analyzed. It was observed that when the water molecules competed with the gas for adsorption under water equilibrium conditions, the electrostatic force (Keeson Force) between the coal molecules and water molecules was much larger than the acting force between the coal molecules and the methane molecules due to the polarity of the water molecules. In addition, there were hydrogen-bond interaction forces between the coal and water molecules of the same order of magnitude, which are referred to as the London Force. Therefore, it was considered that the water molecules were more likely to occupy the adsorption sites of the coal matrix surfaces and then combine with the oxygen-containing functional groups through hydrogen bonds, resulting in the reduction of the gas adsorption amounts of the coal bodies [27].

$Q_{\infty}=\left(\frac{\mathrm{abp}}{1+b p} e^{n\left(T_{\mathrm{s}}-T\right)}-\frac{\mathrm{abp} p_{0}}{1+b p_{0}} e^{n\left(T_{\mathrm{s}}-T_{0}\right)}\right) \frac{1}{1+0.31 M_{a d}} \times \frac{100-A_{a d}-M_{a d}}{100}$,

where $p$ refers to the equilibrium pressure of the coal adsorbed gas (MPa), $a$ indicates the adsorption constant or the limiting adsorption amount of the coal at the test temperature $\left(\mathrm{m}^{3} / \mathrm{t}\right), b$ is the adsorption constant $\left(\mathrm{MPa}^{-1}\right), T_{s}$ represents the test temperature for the determination of $\mathrm{A}$ and $\mathrm{B}$ (K), $T$ denotes the temperature for the gas adsorption test of the coal (K), $M_{a d}$ represents the water mass fraction in the coal body (\%), $n$ is the coefficient, $n=0.02 / 0.993+0.07$ $p, p_{0}$ indicates the atmospheric pressure for the gas desorption test of the coal (MPa), and $T_{0}$ is the ambient temperature of the gas diffusion test of the coal $(\mathrm{K})$.

3.3. Influence Mechanisms of the Water in Regard to the Gas Diffusion and Migration of the Coal Bodies. The internal water and portions of the external water in the coal bodies will combine with the coal surfaces through wetting effects and occupy a certain number of adsorption vacancies on the coal surfaces. Methane molecules are adsorbed in the vacancies not occupied by water molecules and on the surfaces of the first layers of the water molecules. The former then have blocking effects on the surface diffusion of the methane due to the adsorption heat between the water molecules and the coal particle surfaces being high and stable. The latter can reduce the pore diameters to a certain extent and increase the diffusion resistance of the gas molecules after desorption. In particular, the pores with the Knudsen diffusion (diameters less than $100 \mathrm{~nm}$ ) tend to be greatly affected by this factor. In the present study, since the diameters of water molecules were approximately $4 \mathrm{~nm}$, which was equivalent to that of the methane molecules, the water molecules were adsorbed in multiple layers. However, in the small pores that the free water could not reach, since the water had a certain vapor pressure, small amounts of the water molecules existed in the small pores of coal in a gas state, effectively blocking the diffusion channels of methane molecules or increasing the resistance of the transition diffusion and molecular diffusion of the methane gas molecules in the mesopores and macropores. As a result, the diffusion coefficients were reduced.

In this experimental study, in accordance with the influence mechanism of the water in regard to the gas adsorption and desorption in the coal bodies, it was found that injecting a certain amount of water into the coal seam was helpful in controlling the coal seam gas.

\section{Variation Laws of the Mechanical Characteristics of the Coal Bodies under Different Water Content Conditions}

Due to the fact that the stability of the coal bodies in mine working faces is mainly reflected by the shear strength of the coal bodies, and the stability of the coal seam walls in working faces directly affects the release conditions of gas in the coal bodies, coal bodies with poor stability may easily cause sudden gas emissions and result in coal and gas outburst accidents. In order to address these issues, this study mainly used the obtained coal shear strength values to represent the mechanical characteristics of the coal. In addition, the evolution laws of the mechanical characteristics of the coal under different water content conditions were obtained through the conducting of shear tests on the coal. 
4.1. Experimental Design and Equipment. In this experimental investigation, a number of raw coal samples were taken from the No. 8 coal seam of the Xieqiao Coal Mine located in China's Huainan Mining Area. The samples were sealed and transported back to this study's laboratory facilities for drying and crushing. A standard sieve was used to screen out the coal particles with particle sizes less than $2 \mathrm{~mm}$, and $260 \mathrm{~g}$ of the screened coal particles was mixed with water of different masses and allotted numbers. Then, shear tests of coal under different water content conditions were carried out. The experimental results were analyzed in order to determine the variation trends of the shear strength (mechanical characteristics) of different coal bodies under various water content conditions.

\subsection{Experimental Device and Processes}

4.2.1. Experiment Device. This study's experiments were carried out using the available equipment in the National Key Laboratory of Mining Response and Disaster Prevention and Control in Deep Coal Mines at Anhui University of Science and Technology. The equipment included a straincontrolled direct shear apparatus (Figure 2) equipped with the following main components: a shear box, vertical compression frame, dynamometer, driving mechanism, and so on. In addition, a displacement meter (dial indicator) with a range of 5 to $10 \mathrm{~mm}$ and division value $0.01 \mathrm{~mm}$; scale with a weighing value of $500 \mathrm{~g}$ and division value of $0.1 \mathrm{~g}$; cutting ring with an inner diameter $6.18 \mathrm{~cm}$ and height of $2 \mathrm{~cm}$; and a drying oven were utilized in this study's experiments, as shown in Figure 3.

\subsubsection{Experiment Process}

(1) Direct Shear Experiment. First, $80 \mathrm{~g}$ of the coal samples taken from the No. 8 coal seam was placed in the shear box of the direct shear apparatus. The handwheel was turned so that the steel ball at the front end of the upper box had just come in contact with the dynamometer. Then, the dynamometer reading was adjusted to zero. At that point, a gland plate, steel ball, and pressure frame were added successively. $S_{1}$ vertical pressure $(50 \mathrm{kPa})$ was then applied and the fixed pin was pulled out. A stopwatch was started, and a shear pressure at a rate of 0.8 to $1.2 \mathrm{~mm} / \mathrm{min}$ was applied by rotating the handwheel at a uniform speed of 4 to 6 revolutions per minute until the specimen was completely sheared and damage had occurred. The dynamometer readings were measured and recorded for each rotation of the handwheel. In this study's experimental design, $S_{2}(100 \mathrm{kPa}), S_{3}(200 \mathrm{kPa})$, and $S_{4}(400 \mathrm{kPa})$ vertical pressures were successively applied, and the shear parameters of the specimen were measured under the different vertical pressure conditions. The experimental steps were then repeated.

(2) Determination of the Water Content Levels. A portion of the wet coal samples after shear failure were selected and weighed in to obtain the weight $M_{1}$. The sample was dried in a drying oven at $105^{\circ} \mathrm{C}$ to $110^{\circ} \mathrm{C}$ for 24 hours. The sample was removed from the oven and cooled in a dryer to room

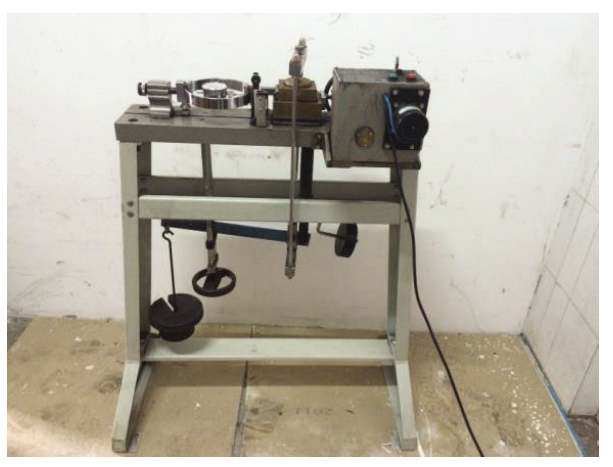

FIGURE 2: ZJ-type strain-controlled direct shear apparatus.

temperature and then weighed for the purpose of obtaining the weight $M_{2}$.

\subsection{Analysis of the Change Rules of the Mechanical Characteristics of the Coal Bodies under Different Water Content Conditions}

4.3.1. Determination of Water Content in the No. 8 Coal Seam. In the present study, in accordance with the weight of the coal samples measured before and after drying, the water content of the different experimental groups of coal was successfully calculated, as shown in Table 1 . The results indicated that the water content levels of the No. 1 to No. 13 samples had increased accordingly with the increases in the pure water mass added into the pulverized coal.

4.3.2. Change Law of the Cohesion of the No. 8 Coal Seam with Different Water Contents. The values of the $S_{1}, S_{2}, S_{3}$, and $S_{4}$ applied pressure experiments were obtained for each group of coal samples. Then, the $S$ values of each group of experiments using the No. 1 to No. 13 samples were linearly fitted. The intercept in the linear fitting results was the cohesion of the coal, in other words, the shear strength of the coal. The shear strength indexes under the different water content conditions are detailed in Table 2.

The change trends of the cohesion with the different water content levels are shown in Figure 4. It was found that when combined with the analysis results shown in Table 2, it could be seen that for the water content in the range of $2.02 \%$ to $18.83 \%$, the cohesion in the coal samples had first increased and then decreased with the increases in water content. In addition, the water content percentages corresponding to the maximum cohesion ranged between $6.77 \%$ and $11.9 \%$, and the water content level at the maximum coal strength was determined to be $8.66 \%$.

\section{Laws of the Gas Diffusion and Migration of the Coal Samples under Different Water Content Conditions}

An experimental method of gas adsorption and desorption of coal bodies was adopted in this study in order to examine the change laws of the gas diffusion amounts and diffusion speeds of the No. 8 coal seam under different water content 


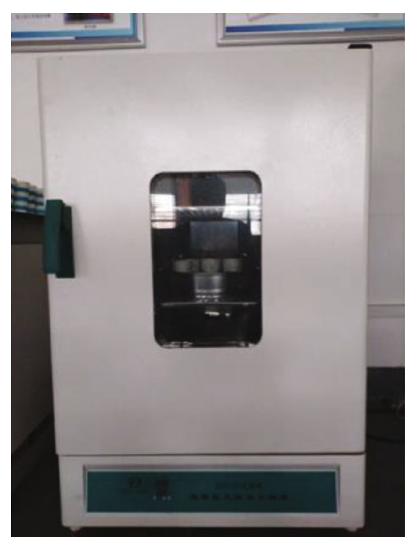

Figure 3: Drying box.

conditions. In addition, the influence laws of the water content in regard to the dynamic processes of the coal particle gas diffusion were explored in order to provide a certain basis for the prediction and prevention of coal and gas outbursts.

This study carried out gas desorption and diffusion experiments using dry coal samples (water content of 0 ), as well as examining coal bodies with water content levels of $2.95 \%, 6.37 \%, 9.24 \%$, and $11.71 \%$, respectively.

5.1. Influence Laws of the Water Content in Regard to the Gas Desorption Speeds. Figure 5 shows the change laws of the gas desorption speeds of the coal bodies in the No. 8 coal seam with time at the water content levels of $0,2.95 \%, 6.37 \%$, $9.24 \%$, and $11.71 \%$, respectively. It can be seen in the figure that the gas desorption speeds of the coal bodies under different water content conditions had gradually decreased over time. The gas desorption speeds were observed to decrease more rapidly during the initial desorption stage, continued to gradually decrease over time, and finally tended to be maintained at 0 . Since the gas desorption speeds have important influencing effects on the amounts of gas desorption and gas release, the larger the desorption speed during the early stages of the gas desorption and release process was, the more favorable the gas desorption effects would be. Meanwhile, the smaller the initial desorption speeds were, the more unfavorable the conditions for gas desorption would be.

Figure 6 details the variation laws of the initial gas desorption speeds with time under the different water content conditions. It can be seen in Figures 5 and 6 that the initial gas desorption speeds under the water content conditions of $0,2.95 \%, 6.37 \%, 9.24 \%$, and $11.71 \%$ in the coal bodies were determined to be $1,775.02 \mathrm{ml} / \mathrm{min}, 1,703.82 \mathrm{ml} / \mathrm{min}$, $1,647.69 \mathrm{ml} / \mathrm{min}, \quad 1,518.93 \mathrm{ml} / \mathrm{min}$, and $1,294.15 \mathrm{ml} / \mathrm{min}$, respectively. Therefore, it was ascertained from the abovementioned results that the gas desorption speeds and initial desorption speeds of the dry coal were the largest. Then, with the increases in water content in the coal bodies, the initial gas desorption speeds and desorption speeds had gradually decreased, and the decreases in the initial gas desorption speeds were faster with the increases in the water content, as shown in Figure 6. During the entire coal gas desorption process, it was found that the lower the water content was, the greater the gas desorption speeds would be. In other words, there was a negative correlation observed between the coal water content levels and the gas desorption speeds. This study determined that, according to the desorption speeds during the latter stage, which had displayed a change curve in the desorption speeds with time, the gas desorption speeds of the coal bodies had still maintained a certain value under the conditions of the low water content. At the same time, the gas desorption speeds of the coal bodies with higher water content basically tended to stabilize to 0 , which showed that lower water content levels resulted in larger gas adsorption amounts, and higher water content levels resulted the lower gas adsorption amounts. That is to say, there was also a negative correlation observed between the coal water content levels and the gas desorption amounts.

\subsection{Influence Laws of the Water Content in Regard to the Gas} Desorption Amounts. Figure 7 details the change laws of the gas desorption amounts with time in the No. 8 coal seam under the water content conditions of $0,2.95 \%, 6.37 \%$, $9.24 \%$, and $11.71 \%$, respectively. It can be seen in the figure that, under the different water content conditions, the gas desorption amounts of the coal bodies had gradually increased with time, and the initial desorption amounts had increased more rapidly. It was observed that with the passage of time, the increased speeds of the gas desorption gradually decreased and finally tended toward a stable value. Since the initial gas desorption speeds of the coal bodies were higher, the gas desorption amounts were also relatively large. Therefore, it was indicated that the larger the gas desorption amount during the initial stage was, the more favorable the gas desorption conditions would be. However, smaller amounts of gas desorption during the initial stage were observed to be unfavorable conditions for the gas desorption processes. In summary, it was found that the smaller the initial gas desorption amounts were, the smaller the instantaneous gas emissions under the site conditions would be, and the more favorable the potential for coal mining would be. However, the larger the initial gas desorption amounts were, the greater the instantaneous gas emissions under the site conditions would be, and the more unfavorable the conditions for coal mining activities would be.

Figure 8 shows the initial gas desorption speeds of the coal bodies under different water content conditions. It can be seen in Figures 7 and 8 that the gas desorption amounts under the water content conditions of $0,2.95 \%, 6.37 \%$, $9.24 \%$, and $11.71 \%$ were $539.74 \mathrm{ml}, 501.71 \mathrm{ml}, 476.23 \mathrm{ml}$, $439.68 \mathrm{ml}$, and $372.26 \mathrm{ml}$, respectively. It was also determined from the above-mentioned results that the maximum gas desorption amount of the dry coal was the largest. However, with the increases in water content levels in coal bodies, the gas desorption amounts had gradually decreased. Moreover, the increases in water content had caused the gas desorption amounts to decrease more violently, as shown in Figure 6. During the entire gas desorption process of coal bodies, it was observed that the lower the water content levels were, the larger the gas desorption amounts would be. A negative correlation was observed between the water content levels of the coal bodies and the gas desorption amount. 
TABLE 1: Determination result of the water content.

\begin{tabular}{|c|c|c|c|c|c|c|c|c|c|}
\hline No. & $\begin{array}{l}\text { Weight } \\
\text { before } \\
\text { drying/g }\end{array}$ & $\begin{array}{l}\text { Weight after } \\
\text { drying/g }\end{array}$ & $\begin{array}{c}\text { Water } \\
\text { content/\% }\end{array}$ & $\begin{array}{l}\text { Average value of } \\
\text { water content } / \%\end{array}$ & No. & $\begin{array}{l}\text { Weight } \\
\text { before } \\
\text { drying/g }\end{array}$ & $\begin{array}{l}\text { Weight after } \\
\text { drying/g }\end{array}$ & $\begin{array}{c}\text { Water } \\
\text { content/\% }\end{array}$ & $\begin{array}{l}\text { Average value of the } \\
\text { water content/\% }\end{array}$ \\
\hline \multirow{4}{*}{1} & 36.98 & 36.19 & 2.18 & \multirow{4}{*}{2.12} & \multirow{4}{*}{8} & 46.48 & 41.43 & 46.48 & \multirow{4}{*}{11.90} \\
\hline & 42.09 & 41.18 & 2.21 & & & 36.08 & 32.21 & 36.08 & \\
\hline & 37.78 & 37.01 & 2.08 & & & 27.6 & 24.69 & 27.6 & \\
\hline & 43.95 & 43.09 & 2.00 & & & 55.24 & 49.49 & 55.24 & \\
\hline \multirow{4}{*}{2} & 43.05 & 41.48 & 3.78 & \multirow{4}{*}{3.60} & \multirow{4}{*}{9} & 48.26 & 42.2 & 48.26 & \multirow{4}{*}{13.96} \\
\hline & 46 & 44.36 & 3.70 & & & 46.38 & 40.6 & 46.38 & \\
\hline & 50.54 & 48.81 & 3.54 & & & 42.5 & 37.25 & 42.5 & \\
\hline & 60.34 & 58.38 & 3.36 & & & 43.39 & 38.35 & 43.39 & \\
\hline \multirow{4}{*}{3} & 41.03 & 39.01 & 5.18 & \multirow{4}{*}{4.98} & \multirow{4}{*}{10} & 37.58 & 32.22 & 37.58 & \multirow{4}{*}{16.64} \\
\hline & 53.45 & 50.88 & 5.05 & & & 53.24 & 45.46 & 53.24 & \\
\hline & 47.46 & 45.25 & 4.88 & & & 37.38 & 32.09 & 37.38 & \\
\hline & 56.09 & 53.52 & 4.80 & & & 52.69 & 45.29 & 52.69 & \\
\hline \multirow{4}{*}{4} & 46.35 & 43.58 & 6.36 & \multirow{4}{*}{6.77} & \multirow{4}{*}{11} & 55.37 & 46.41 & 55.37 & \multirow{4}{*}{19.21} \\
\hline & 24.88 & 23.32 & 6.69 & & & 59.11 & 49.42 & 59.11 & \\
\hline & 58.79 & 54.92 & 7.05 & & & 47.02 & 39.67 & 47.02 & \\
\hline & 48.77 & 45.58 & 7.00 & & & 48.45 & 40.58 & 48.45 & \\
\hline \multirow{4}{*}{5} & 44.47 & 40.86 & 44.47 & \multirow{4}{*}{8.66} & \multirow{4}{*}{12} & 46.6 & 39 & 46.6 & \multirow{4}{*}{19.01} \\
\hline & 40.2 & 36.97 & 40.2 & & & 33.83 & 28.52 & 33.83 & \\
\hline & 42.66 & 39.22 & 42.66 & & & 42.25 & 35.62 & 42.25 & \\
\hline & 49.32 & 45.54 & 49.32 & & & 56.39 & 47.26 & 56.39 & \\
\hline \multirow{4}{*}{6} & 48.68 & 44.11 & 48.68 & \multirow{4}{*}{10.18} & \multirow{4}{*}{13} & 57.53 & 47.12 & 57.53 & \multirow{4}{*}{21.93} \\
\hline & 43.41 & 39.35 & 43.41 & & & 54.59 & 44.71 & 54.59 & \\
\hline & 35.16 & 31.91 & 35.16 & & & 53.66 & 43.95 & 53.66 & \\
\hline & 50.01 & 45.52 & 50.01 & & & 45.24 & 37.26 & 45.24 & \\
\hline \multirow{4}{*}{7} & 57.69 & 49.57 & 57.69 & \multirow{4}{*}{15.40} & & & & & \\
\hline & 57.57 & 49.55 & 57.57 & & & & & & \\
\hline & 58.08 & 50.6 & 58.08 & & & & & & \\
\hline & 60.67 & 53.11 & 60.67 & & & & & & \\
\hline
\end{tabular}

TABLE 2: Shear strength index under different water content conditions.

\begin{tabular}{lcccccccc}
\hline No. & Water content $(\%)$ & $\begin{array}{c}S_{1} \\
(\mathrm{kPa})\end{array}$ & $\begin{array}{c}S_{2} \\
(\mathrm{kPa})\end{array}$ & $\begin{array}{c}S_{3} \\
(\mathrm{kPa})\end{array}$ & $\begin{array}{c}S_{4} \\
(\mathrm{kPa})\end{array}$ & $\begin{array}{c}\text { Cohesion } \\
c(\mathrm{kPa})\end{array}$ & $\begin{array}{c}\text { Tan } \\
\varphi\end{array}$ & $\begin{array}{c}\text { Angle of internal friction } \\
\varphi\left({ }^{\circ}\right)\end{array}$ \\
\hline 1 & 2.12 & 8.963 & 15.588 & 31.956 & 62.353 & 0.881 & 0.154 & 8.744 \\
2 & 3.60 & 8.262 & 16.368 & 30.397 & 63.132 & 0.251 & 0.156 & 8.878 \\
3 & 4.98 & 9.548 & 16.173 & 34.684 & 64.106 & 1.576 & 0.158 & 8.956 \\
4 & 6.77 & 8.963 & 16.173 & 31.566 & 59.235 & 2.025 & 0.144 & 8.183 \\
5 & 8.66 & 9.353 & 18.511 & 33.515 & 62.158 & 2.914 & 0.149 & 8.486 \\
6 & 10.18 & 9.821 & 16.952 & 31.761 & 60.209 & 2.665 & 0.144 & 8.200 \\
7 & 11.90 & 9.431 & 17.147 & 30.202 & 59.625 & 2.360 & 0.143 & 8.116 \\
8 & 13.96 & 9.431 & 15.588 & 28.448 & 59.625 & 1.234 & 0.144 & 8.205 \\
9 & 15.40 & 8.379 & 15.276 & 29.812 & 60.794 & 0.385 & 0.150 & 8.548 \\
10 & 16.64 & 8.184 & 15.783 & 27.864 & 60.015 & 0.322 & 0.147 & 8.385 \\
11 & 19.21 & 8.184 & 15.588 & 31.566 & 60.989 & 0.737 & 0.151 & 8.598 \\
13 & 19.01 & 8.768 & 16.173 & 32.151 & 61.963 & 1.203 & 0.152 & 8.660 \\
\hline
\end{tabular}




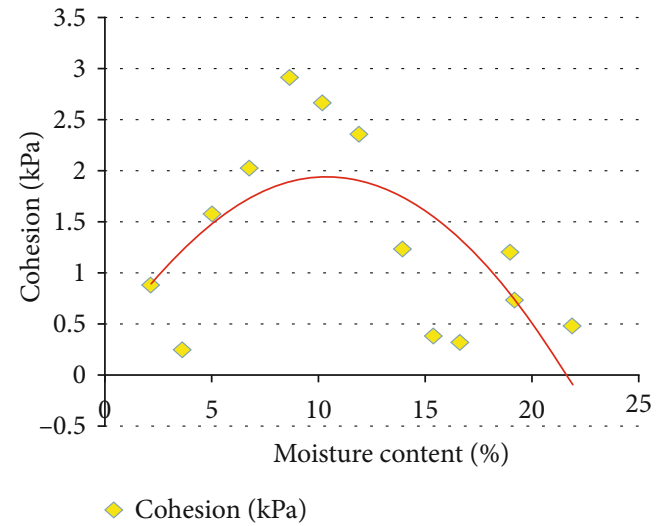

Figure 4: Change trends of the cohesion with different water content levels in the coal samples.

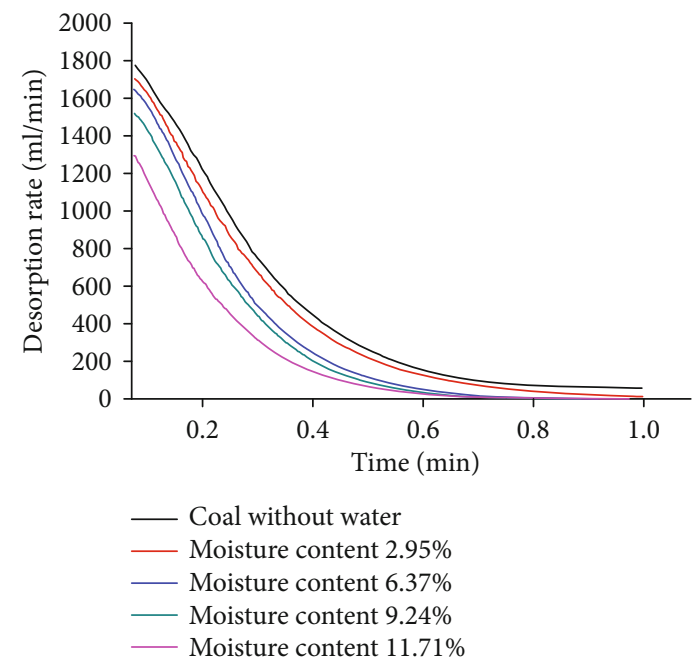

Figure 5: Comparison diagram of the change laws of the gas desorption speeds with time under different water content conditions.

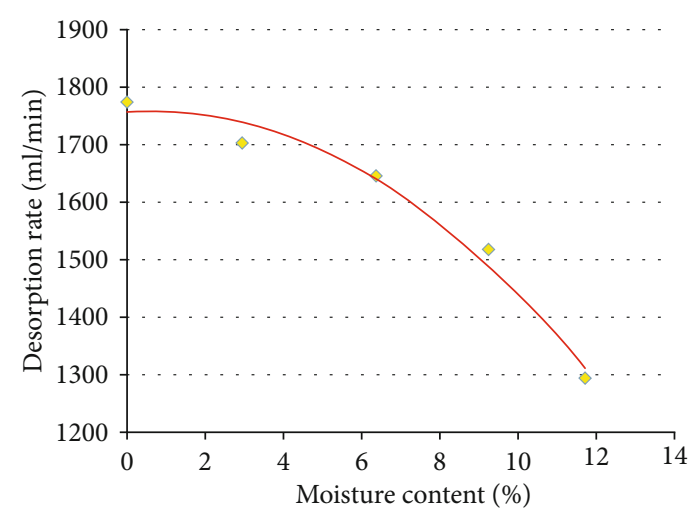

FIGURE 6: Initial gas desorption speed of the coal bodies under different water content conditions.

Furthermore, according to the last stage of the change curve of the desorption amounts with time, the gas desorption

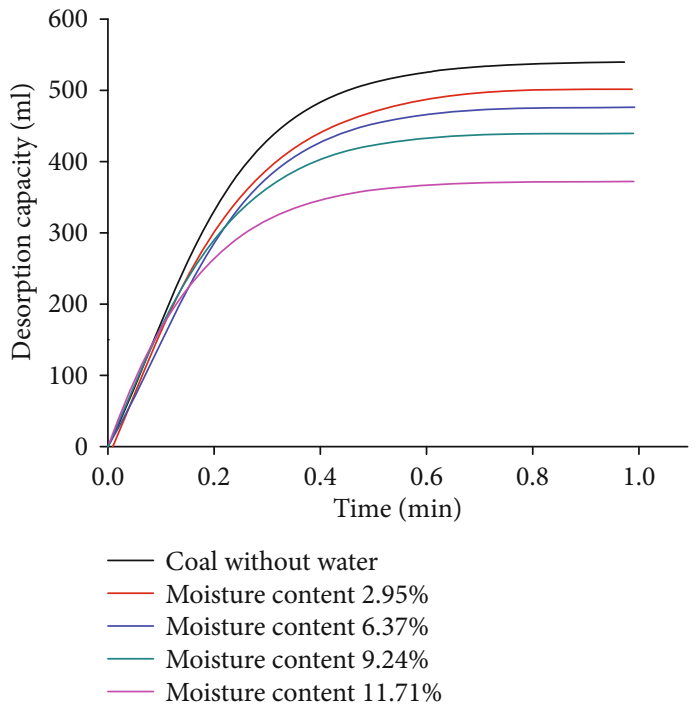

Figure 7: Comparison diagram for the change laws of the gas desorption amounts with time under different water content conditions.

amounts of the coal bodies under the condition of low water content were still on the rise, while the gas desorption amounts of the coal with higher water content had basically tended to enter a stable state. It was also found that in accordance with the gas desorption speeds, the lower the water content levels in the coal bodies was, the stronger the gas adsorption capacity would be, and the larger the gas adsorption force would be. It could be seen form this study's results that the higher the water content levels were, the weaker the gas adsorption capacity would be. In summary, there was also a negative correlation observed between the coal water content levels and the gas adsorption capacity.

It was indicated from the aforementioned study results that the gas adsorption capacities of the coal bodies were negatively correlated with the water content levels. This was determined to have been caused by the fact that the interaction force between the water and coal particles was far greater than that between the methane molecules (gas) and coal particles. This had led to the coal bodies having weaker gas adsorption capacities with the higher water content. Therefore, there was also a negative correlation between the gas desorption process and diffusion speeds and the water content levels in the coal bodies. This was attributed to the fact that the existence of the water had blocked the diffusion channels of the methane molecules, increased the resistance to the transition diffusion and molecular diffusion of the methane gas molecules in the mesopores and macropores of the coal bodies, and reduced the diffusion coefficients. Therefore, it was concluded that the higher the water content levels were, the lower the gas diffusion speeds of the coal bodies would be.

\section{Conclusions}

This study examined the solid-liquid-gas three-phase coupling relationship between coal, water, and gas and revealed 


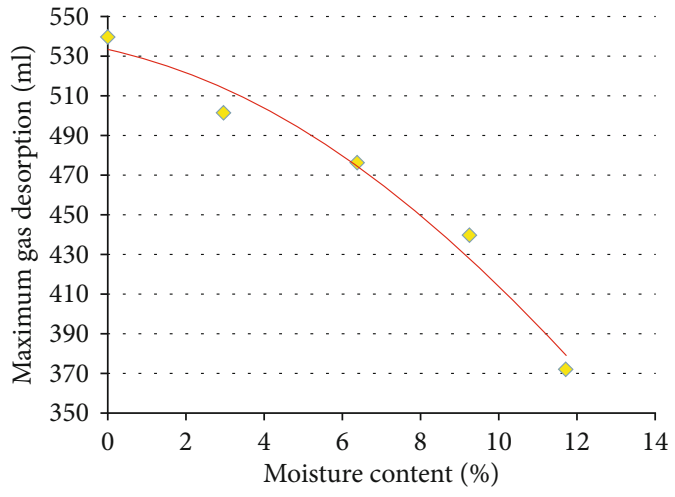

FIGURE 8: Maximum gas adsorption amounts of the coal bodies with different water content levels.

the influence mechanisms of water on the mechanical characteristics of coal bodies, as well as gas diffusion and migration processes. This study's results also revealed the evolution laws of the mechanical characteristics of coal bodies and gas diffusion and migration laws under different water content conditions. The research results have important guiding significance for the improvement of mechanical properties of high-gas coal seam and gas control and can effectively prevent the occurrence of coal wall spalling and gas outburst. The following conclusions were obtained in this study:

(1) This study experimental examination of the mechanical characteristics of the coal bodies under different water content conditions revealed that with the increases in water content, the mechanical characteristics presented a change trend of first increasing and then decreasing. The water content levels which corresponded to the maximum shear strength of the No. 8 coal seam in the study area were determined to be in the range of $6.77 \%$ to $11.9 \%$. The water content level which corresponded to the extreme value point was $8.66 \%$. The results obtained in this study suggested that reasonable water injection processes should be carried out to improve the strength of coal bodies in working faces. It was considered that by improving the physical and mechanical characteristics of the coal bodies, the stability could be improved, and the spalling of the coal walls could be prevented

(2) The results of this experimental study also indicated that the gas desorption speeds of the coal bodies had gradually decreased with time under the different water content conditions. It was observed that the gas desorption speeds rapidly decreased during the initial desorption stage, yet the speed decreases became gradually slower with time. In addition, it was found that under the different water content conditions, the gas desorption amounts in the coal bodies gradually increased with time, with the initial desorption amounts displaying rapid increases. Then, with the passage of time, the increase speeds of the gas desorp- tion amounts were found to gradually decrease and finally tended toward a stable value state

(3) It was observed in this study that the dry coal samples had the largest gas desorption and initial desorption speeds and the highest desorption amounts. However, with the increases in the water content, the gas desorption speeds, initial desorption speeds, and desorption amounts of the coal bodies were found to continuously decrease. That is to say, the water content levels in the coal bodies were found to be negatively correlated with the gas desorption speeds and desorption amounts, and the above-mentioned parameter values had changed more noticeably with the increases in the water content levels.

\section{Data Availability}

The data used to support the findings of this study are included within the article.

\section{Conflicts of Interest}

The authors declare that there are no conflicts of interest regarding the publication of this paper.

\section{Acknowledgments}

This research was funded by the Natural Science Foundation of Anhui Province (No. 1908085QE226, 908085QE186, and 1908085QE184), Natural Science Foundation of the Anhui Higher Education Institutions (KJ2018A0077), Independent Project of State Key Laboratory of Mining-induced Response and Disaster Prevention and Control in Deep Coal Mines (SKLMRDPC19ZZ02), National Natural Science Foundation of China (51874006), National Key R\&D Program of China (No. 2017YFC0804202), and Science Research Foundation for Young Teachers of Anhui University of Science and Technology (No. QN2018117).

\section{References}

[1] Y. Wang, H. Zhang, H. Lin, Y. Zhao, and Y. Liu, "Fracture behaviour of central-flawed rock plate under uniaxial compression," Theoretical and Applied Fracture Mechanics, vol. 106, article 102503, 2020.

[2] Y. X. Wang, P. P. Guo, W. X. Ren et al., "Laboratory investigation on strength characteristics of expansive soil treated with jute Fiber reinforcement," International Journal of Geomechanics, vol. 17, no. 11, article 04017101, 2017.

[3] Y. Zhao, L. Zhang, W. Wang, W. Wan, and W. Ma, "Separation of elastoviscoplastic strains of rock and a nonlinear creep model," International Journal of Geomechanics, vol. 18, no. 1, article 04017129, 2018.

[4] Y. Zhao, Y. Wang, W. Wang, L. Tang, Q. Liu, and G. Cheng, "Modeling of rheological fracture behavior of rock cracks subjected to hydraulic pressure and far field stresses," Theoretical and Applied Fracture Mechanics, vol. 101, pp. 59-66, 2019.

[5] J. Wang, J. Ning, P. Qiu, S. Yang, and H. Shang, "Microseismic monitoring and its precursory parameter of hard roof collapse 
in longwall faces: a case study," Geomechanics and Engineering, vol. 17, no. 4, pp. 375-383, 2019.

[6] S. Xie, H. Lin, Y. Wang et al., "A statistical damage constitutive model considering whole joint shear deformation," International Journal of Damage Mechanics, vol. 29, no. 6, pp. 9881008, 2020.

[7] H. Lin, H. Yang, Y. Wang, Y. Zhao, and R. Cao, "Determination of the stress field and crack initiation angle of an open flaw tip under uniaxial compression," Theoretical and Applied Fracture Mechanics, vol. 104, article 102358, 2019.

[8] S. Valliappan and Z. Wohua, "Numerical MODELLING of methane gas migration in dry coal seams," International Journal for Numerical and Analytical Methods in Geomechanics, vol. 20, no. 8, pp. 571-593, 1996.

[9] Y. X. Wang, P. Guo, H. Lin et al., "Numerical analysis of fiberreinforced soils based on the equivalent additional stress concept," International Journal of Geomechanics, vol. 19, no. 11, article 04019122, 2019.

[10] C. Z. Pu, P. Cao, Y. Chen, Y. L. Yi, and X. Y. Zhang, "Fracture test and failure mechanism of rock-like material of relatively different fracture apertures," Journal of Central South University(Science and Technology), vol. 42, no. 8, pp. 2394-2399, 2011.

[11] G. Xie, Z. Yin, L. Wang, Z. Hu, and C. Zhu, "Effects of gas pressure on the failure characteristics of coal," Rock Mechanics and Rock Engineering, vol. 50, no. 7, pp. 1711-1723, 2017.

[12] Z. Q. Yin, Z. X. Hu, Z. D. Wei et al., “Assessment of blastinginduced ground vibration in an open-pit mine under different rock properties," Advances in Civil Engineering, vol. 2018, Article ID 4603687, 10 pages, 2018.

[13] Z. Yin, W. Chen, H. Hao et al., "Dynamic compressive test of gas-containing coal using a modified split Hopkinson pressure bar system," Rock Mechanics and Rock Engineering, vol. 53, no. 2, pp. 815-829, 2020.

[14] B. X. Yuan, L. Xiong, L. Zhai et al., “Transparent synthetic soil and its application in modeling of soil-structure interaction using optical system," Frontiers in Earth Science, vol. 7, p. 276, 2019.

[15] L. Jia, K. Li, J. Zhou, Z. Yan, Y. Wang, and B. M. Mahlalela, "Experimental study on enhancing coal-bed methane production by wettability alteration to gas wetness," Fuel, vol. 255, article 115860, 2019.

[16] B. X. Yuan, M. Sun, L. Xiong, Q. Luo, S. P. Pradhan, and H. Li, "Investigation of 3D deformation of transparent soil around a laterally loaded pile based on a hydraulic gradient model test," Journal of Building Engineering, vol. 28, no. 3, article 101024, 2020.

[17] L. He, L. Yong, L. Kunchao, Z. Long, T. Miaozhuang, S. Te et al., "Study on dynamic change characteristics for producing water and gas in CBM well," Urban Geology, vol. 13, no. 4, pp. 60-66, 2018.

[18] S. Peng, "Research on influence rules of gas content and water content in low permeability coal seam after repeated hydraulic fracturing," in International Conference on Environmental Protection, Coal Industry and Metallurgical Mine Safety (EPCIMMS 2019), pp. 91-96, Qingdao, Shandong, China, 2019.

[19] L. Hua-chao, L. Xue-long, and Z. Liang, "Research on hydraulic fracturing in low permeability soft coal seam," Coal technology, vol. 33, no. 10, pp. 16-19, 2014.

[20] D. U. Feng, "Research on drilling parameters of directional hydraulic fracturing gas extraction in deep and low permeabil- ity coal seam," Coal Technology, vol. 37, no. 10, pp. 245-248, 2018.

[21] B. X. Yuan, M. Sun, Y. X. Wang, L. H. Zhai, Q. Z. Luo, and $\mathrm{X}$. Zhang, "Full 3D displacement measuring system for 3D displacement field of soil around a laterally loaded pile in transparent soil," International Journal of Geomechanics, vol. 19, no. 5, article 04019028, 2019.

[22] L. Haijin and V. Dept, "Practical research on hydraulic fracturing of directional long drilling in soft coal seam," Jiangxi Coal Science \& Technology, vol. 38, no. 3, pp. 20-23, 2017.

[23] F. Cai and Z. G. Liu, "Simulation and experimental research on upward cross-seams hydraulic fracturing in deep and lowpermeability coal seam," Journal of China Coal Society, vol. 41, no. 1, pp. 113-119, 2016.

[24] X. X. Chen, Y. K. Zhang, Y. Xu, and R. Q. Bi, “The new technology of hydraulic fracturing soft coal rock permeability improvement," Advanced Materials Research, vol. 1030-1032, pp. 1255-1259, 2014.

[25] C. Zhu, Experimental study on mechanical characteristics and improvement of soil like coal and rock mass, Anhui University of Science and Technology, 2014.

[26] L. Yanwei, Z. Jiaqi, L. Mingju, and L. Yapeng, "Influence of moisture content on gas diffusion coefficient of coal particles with different metamorphic degree," Journal of Safetyscience and Technology, vol. 11, no. 6, pp. 12-17, 2015.

[27] L. Yanwei and X. Wentao, "Influence of moisture on dynamic process of coal particle gas diffusion," Journal of safety and environment, vol. 16, no. 1, pp. 62-66, 2016. 